\title{
Performance of Reinforced Concrete Beams with Implanted Columns
}

\author{
Ahmed S. Rashed and Yasser R. Zaghloul* \\ Civil Engineering Department, Higher Institute of Engineering, El-Shorouk City, Cairo, Egypt \\ Received 02 Nov 2017, Accepted 01 Jan 2018, Available online 02 Jan 2018, Vol.8, No.1 (Jan/Feb 2018)
}

\begin{abstract}
The main aim of this study is to specify the behavior of the beams related to the carried implanted column corresponding to the column direction and its location in both bending and shear cases and to give some recommendations and specifications which can be taken into consideration while the design of beams has an implanted column. The experimental study was achieved by testing five full-scale beams with respect to the failure load, deflection and strain in steel reinforcement. Results showed that the best position for the implanted column in the bending case is when the length of the implanted column is perpendicular to beam span. Furthermore, the design of the beam is sufficient and conservative in presence of implanted column near the support to satisfy the shear formed by the applied load.
\end{abstract}

Keywords: Beams; implanted columns; shear stresses; bending stresses.

\section{Introduction}

Reinforced concrete beams are common elements in more than $80 \%$ of the structures around the world. They are used as horizontal members transferring the load from the slabs to the vertical members, and for stiffening the structure, by connecting the columns together creating a stiff structural system. On the other hand, the reinforced concrete beams can be used as transfer girders and for supporting newly planted columns in which changing in the structure plan is required. Moreover, columns are the most important compression members which transmit loads from the top to the lower levels, and then to the soil through the foundations. Changing columns locations or its directions through different floors levels may cause many problems if not taken in design considerations. Accordingly, beams are the most efficient members that can be used in supporting these columns, but unfortunately, there are no specifications in different codes of practice for the design of beams that have implanted columns, considering the direction of column, its dimensions, and the place of the column from supports of the beams. Therefore, it becomes so vital to study the effect of these last factors on both shear and bending stresses.

Implanted column is a structural member which is seated on top of a non-axial bearing member and may consider as concentrated load on the beam. Some researchers are reported in the field of studying the behavior of reinforced concrete beams under

*Corresponding author's ORCID ID: 0000-0002-4172-7893 DOI: https://doi.org/10.14741/ijcet.v8i01.10882 concentrated loads in both bending and shear. Kokusho et al (1988, studied the bending shear experiment of rectangular beam and T-shaped beam which performed to consider the effect of axial restriction of deformation, through a simple analysis. The result showed that, when the beam was subjected to an axial restriction of deformation, a compressive force acted on the beam, caused the strength of the beam to increase at a greater ratio ranged from 1.5 to 2 times than that in the case of an unrestricted beam. Hansapinyo et al (2003), have tested thirteen reinforced concrete beams with square and rectangular sections to investigate ultimate capacity under bi-axial shear loading and the ultimate bi-axial shear capacities of concrete and shear reinforcement were defined separately.

The test results showed that the ellipse formula was underestimated bi-axial shear capacity of concrete while it was overestimated bi-axial shear capacity of shear reinforcement of specimens with a rectangular section. Chaisomphob et al (2003), have presented the experimental investigation on the failure mechanism and ultimate capacity of rectangular reinforced concrete beam under combined action of bi-axial shear accompanied with torsion through the test of four reinforced concrete members. The results showed that the increase in the magnitude of torsion to about $69 \%$ reduced bi-axial shear capacity as much as $12 \%$ to $39 \%$ according to the ratio of bi-axial shears. Also, Waryosh et al (2014), investigated the mechanism of failure and the maximum loading capacity of rectangular reinforced concrete beam under bi-axial shear load through the test of eight reinforced concrete beams. 
They concluded that the calculated values from the ellipse formula using the ACI and JSCE codes give quite conservative values of ultimate capacity compared with experimental results.

Accordingly, the present work will be directed to study the behavior of the reinforced concrete beams constructed to carry an implanted column.

\section{Testing Program}

This section describes the experimental work performed through this study

\subsection{Materials Used}

Ordinary locally available concrete constituent materials have been used to manufacture the test specimens. All specimens are made from one concrete mix with the proportion shown in Table 1 . The target standard 28-days compressive strength for the cube is $f_{c u}=25 \mathrm{MPa}$, and consequently, the equivalent compressive strength for the cylinder is $f_{c}^{\prime}=20 \mathrm{MPa}$. The results of testing cubes have satisfied the target strength.

Table 1: Mix design proportion (Characteristic Strength=25 $\mathrm{MPa}$ )

\begin{tabular}{|c|c|c|c|c|}
\hline Material & Dolomite & Sand & Cement & Water \\
\hline Mix Proportion $\left(\mathrm{Kg} / \mathrm{m}^{3}\right)$ & 1305 & 615 & 350 & 175 \\
\hline
\end{tabular}

The specimen's main reinforcement(longitudinal) is of high grade deformed steel bars with $360 \mathrm{MPa}$ nominal yield stress while the lateral reinforcement (stirrups) is mild smooth bars with $240 \mathrm{MPa}$ nominal yield stress.

\subsection{Specimens Details}

In the experimental program, all beams have a rectangle section of $37.5 \times 40 \mathrm{~cm}$ and $2000 \mathrm{~mm}$ span, each beam has an implanted column with rectangular cross section of $120 \times 375$ and reinforced with 6Ф12 as along reinforcement and stirrups are Ø8@150 mm (grade 24/35). The details of all specimens are shown in Figures 1 to 5. The lower reinforcement was 4Ф16 (grade 36/52), while upper reinforcement was $4 \Phi 12$ (grade 36/52) and stirrups of $\varnothing 8 @ 150$ mm. (grade 24/35). The implanted column location and its direction differ from specimen to another according to its case study. The experimental program was undertaken to present the effect of the implanted column direction, while located in bending and shear zones, on the capacity of the beam for the carrying load. Furthermore, to present its behavior to achieve this goal, in bending zone three specimens (S1, S2, and S3) and in shearing zone two specimens (S4 and S5) were taken in tests as shown in Table 2.

\subsection{Measuring Devices}

A load cell with a capacity of 150 ton was used which is connected to measurement unit for obtaining applied load. Also, two dial gauges with an accuracy of $0.01 \mathrm{~mm}$

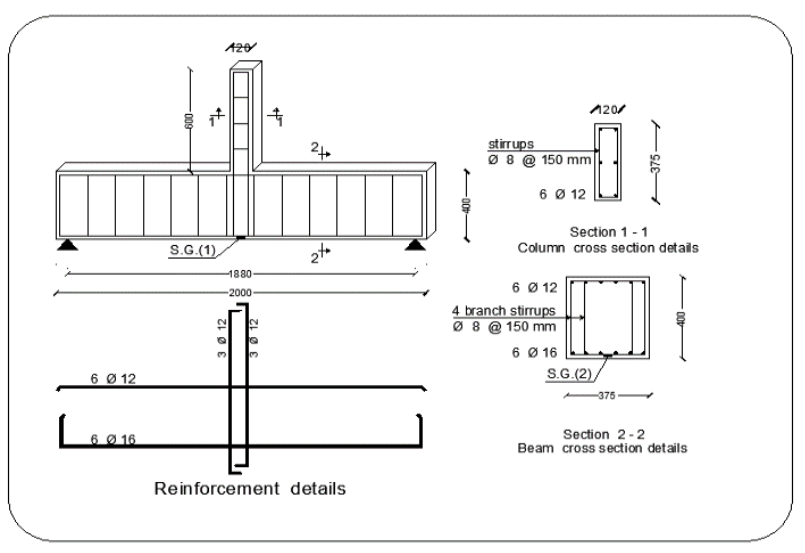

Figure 1: Details of specimen S1

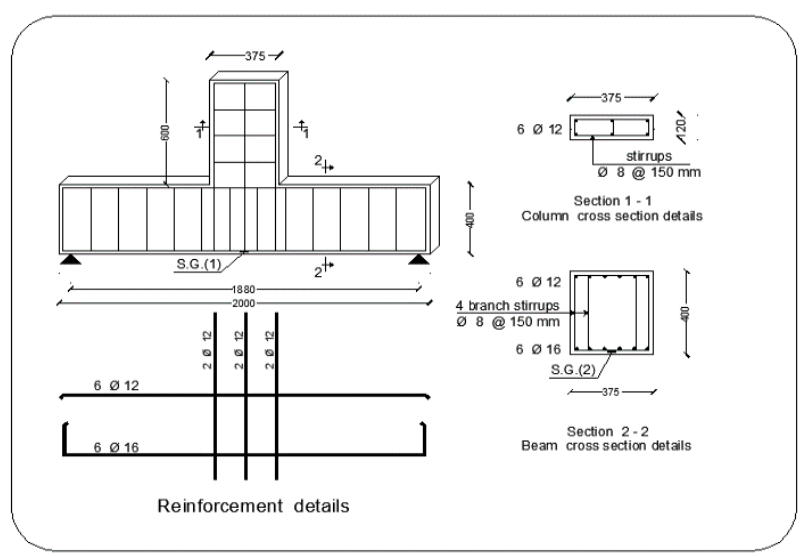

Figure 2: Details of specimen S2

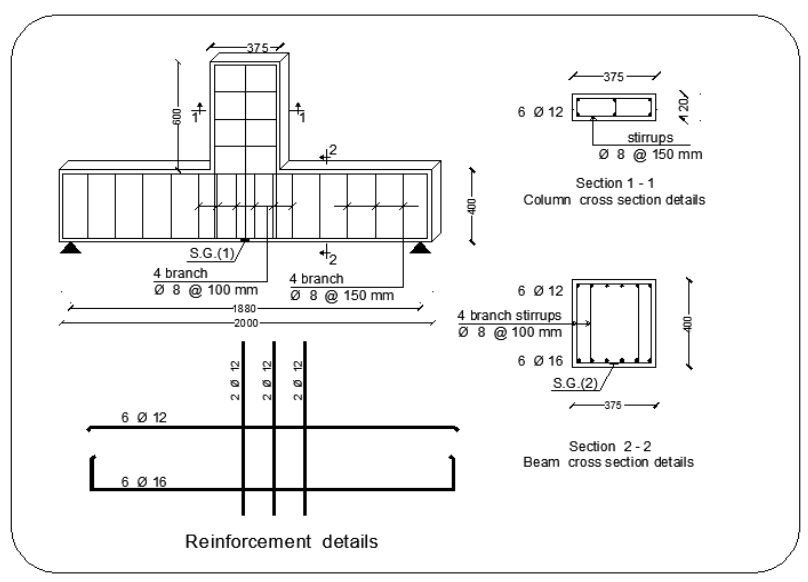

Figure 3: Details of specimen S3 


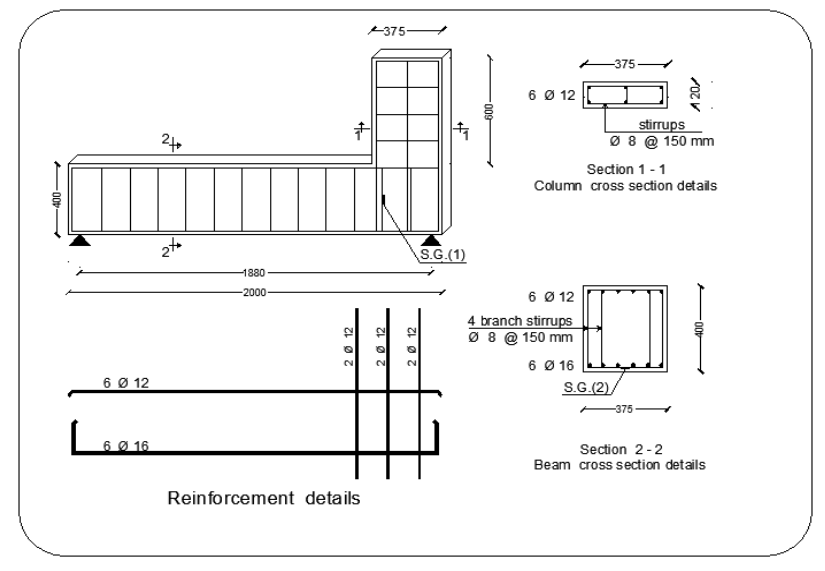

Figure 4: Details of specimen S4

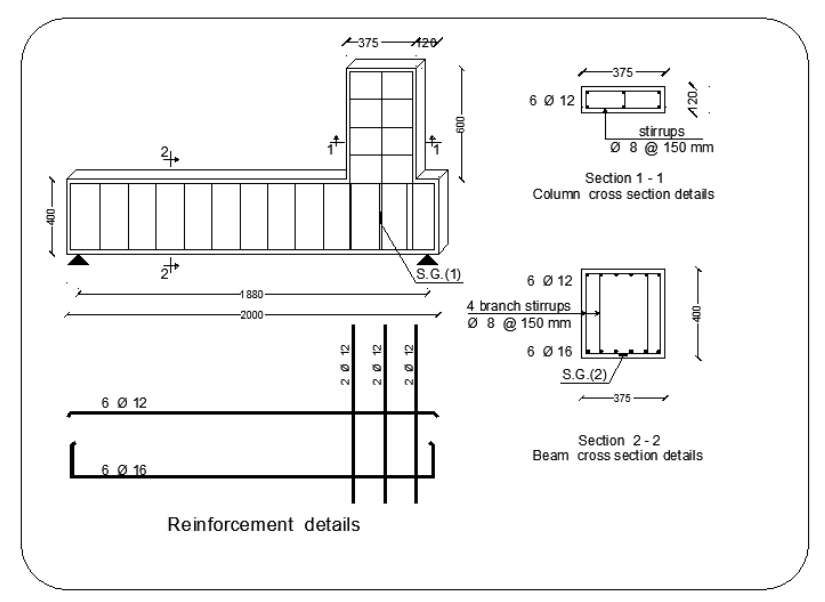

Figure 5: Details of specimen S5

Table 2: Specimens Identification

\begin{tabular}{|c|c|}
\hline $\begin{array}{c}\text { Specimen } \\
\text { (S1) }\end{array}$ & $\begin{array}{c}\text { The long side of column direction is } \\
\text { perpendicular to the beam span at the mid span } \\
\text { of the beam }\end{array}$ \\
\hline $\begin{array}{c}\text { Specimen } \\
\text { (S2) }\end{array}$ & $\begin{array}{c}\text { The long side of column direction is parallel to } \\
\text { the beam span at the center line and mid span of } \\
\text { the beam }\end{array}$ \\
\hline $\begin{array}{c}\text { Specimen } \\
\text { (S3) }\end{array}$ & $\begin{array}{c}\text { The same as the specimen S2 but with increasing } \\
\text { the stirrups distribution to Ø8 @100 mm under } \\
\text { the column at the bending zone to present its } \\
\text { effect on the carrying load }\end{array}$ \\
\hline $\begin{array}{c}\text { Specimen } \\
\text { (S4) }\end{array}$ & $\begin{array}{c}\text { The long side of column direction is parallel to } \\
\text { the beam span at the end of the beam at the shear } \\
\text { zone }\end{array}$ \\
\hline $\begin{array}{c}\text { Specimen } \\
\text { (S5) }\end{array}$ & $\begin{array}{c}\text { The long side of column direction is parallel to } \\
\text { the beam span at 120 mm far from the end of the } \\
\text { beam at the shear zone }\end{array}$ \\
\hline
\end{tabular}

were used to measure the deformation of beams. Electrical strain gauges with $13 \mathrm{~mm}$ length, 119.8 \pm 0.2 Ohms resistance, and gauge factor $2.11 \pm 1 \%$ were used to measure the longitudinal strain of tension steel rebar and stirrups under implanted columns. The strain gauges were connected to a strain meter device with an accuracy of $1 \times 10^{-6}$ and covered by a waterproof coating to protect them from water and damage during casting. At every stage of loading, cracks were observed and marked, if any. In addition, the strains are recorded automatically using a data acquisition system. Finally, the deflection was measured using electronic gauges which were connected to the measurement device with accuracy of $0.01 \mathrm{~mm}$.

\subsection{Test Setup}

The specimens were tested up to failure using the testing frame shown in Fig. 6. A load cell of $1000 \mathrm{KN}$ capacity was used which is connected to a digital display unit.

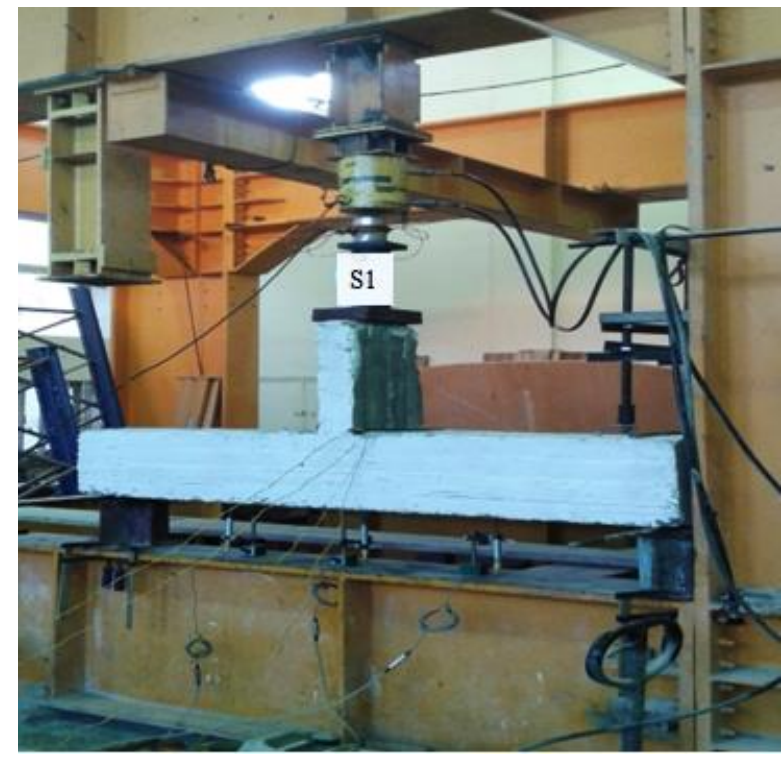

Figure 6: Test Setup

\section{Results}

This section describes the experimental test results. Table 3 shows the results of the first crack load, failure load and failure type for all the investigated specimens. While Table 4 shows the maximum deflection at the failure load for the five specimens.

The behavior of the beams having implanted columns differ than ordinary beams as the changing in the direction of the implanted column has a great effect on the failure load of the beam. The deflections of all beams have been measured at each increment of loading. Figure 7.a to Figure 11.a show the loaddeflection curves for all tested Beams. Three electronic gauges were located at loading points $500 \mathrm{~mm}, 1000$ $\mathrm{mm}$ and $1500 \mathrm{~mm}$ from the left support of the beam to detect the deflection on these locations, Figs. 7.b to 11.b. All deflection curves indicated that the first three specimens have almost the same profile where the first parts of the curves are steep in elastic zone. After cracks, most of the profiles started to be different and more curved till the failure occurred in plastic zone. Also, it is to be noted that the load increases as the deflection and strains increase until the longitudinal steel reached yield strain in the first three specimens (bending case). Maximum load for all beams was recorded as presented in Table 3. 
Table 3: First Crack, Ultimate loads, and Failure type

\begin{tabular}{|c|c|c|c|c|}
\hline Specimen & Type & $\begin{array}{l}\text { First Crack load } \\
\text { (KN) }\end{array}$ & $\begin{array}{c}\text { Failure } \\
\text { load }(\mathrm{KN})\end{array}$ & Failure type \\
\hline S1 & $\begin{array}{l}\text { Bending } \\
\text { Implanted column perpendicular to span }\end{array}$ & 230 & 338.3 & $\begin{array}{l}\text { Tension } \\
\text { failure }\end{array}$ \\
\hline S2 & $\begin{array}{c}\text { Bending } \\
\text { Implanted column parallel to span }\end{array}$ & 127 & 292.7 & $\begin{array}{l}\text { Tension } \\
\text { failure }\end{array}$ \\
\hline S3 & $\begin{array}{c}\text { Bending } \\
\text { Implanted column parallel to span with } \\
\text { increasing stirrups under column }\end{array}$ & 225 & 367.9 & $\begin{array}{l}\text { Tension } \\
\text { failure }\end{array}$ \\
\hline S4 & $\begin{array}{c}\text { Shear } \\
\text { Implanted column parallel to span at the end } \\
\text { of the beam }\end{array}$ & 490 & 490 & $\begin{array}{l}\text { Compression } \\
\text { failure in planted column }\end{array}$ \\
\hline S5 & $\begin{array}{l}\text { Shear } \\
\text { Implanted column parallel to span at } 120 \mathrm{~mm} \\
\text { from the end of the beam }\end{array}$ & 460 & 460 & $\begin{array}{l}\text { Compression } \\
\text { failure in planted column }\end{array}$ \\
\hline
\end{tabular}

Table 4: Maximum deflection at failure load

\begin{tabular}{|c|c|c|c|c|c|}
\hline Specimen Code & S1 & S2 & S3 & S4 & 490 \\
\hline Failure Load (KN) & 338.3 & 292.7 & 367.9 & 460 & 2.503 \\
\hline Maximum deflection (mm) & 8.698 & 6.413 & 5.326 & 1.803 & At 1500mm from left \\
\hline Location & Mid. span & Mid. span & Mid. span & At 1500mm from left & A \\
\hline
\end{tabular}

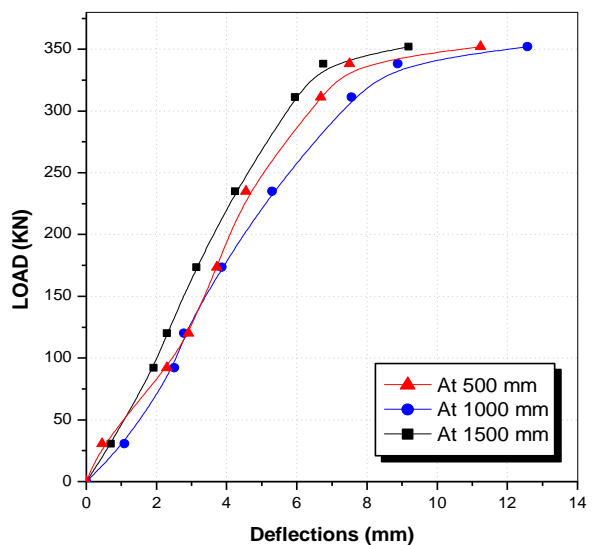

(a)

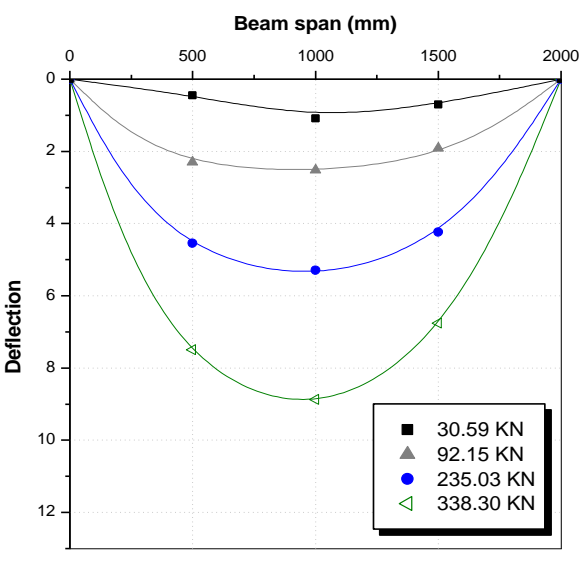

(b)

Fig. 7: Load-deflection and deflection location curves for specimen S1

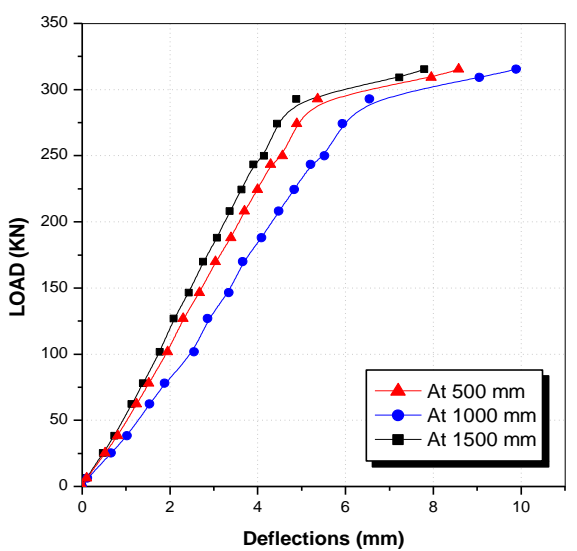

(a)

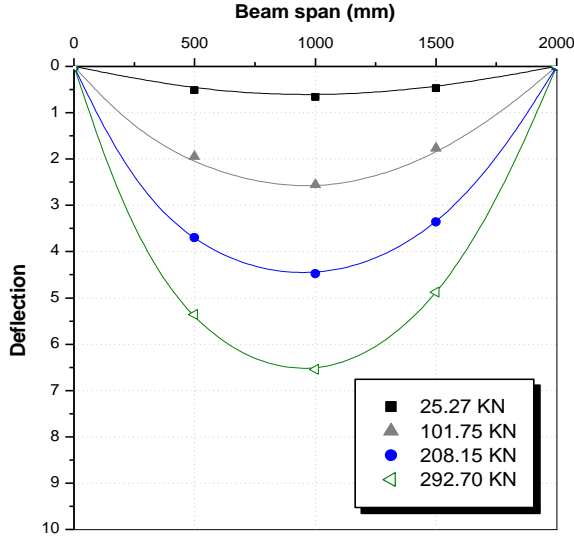

(b)

Fig.8: Load-deflection and deflection location curves for specimen S2 


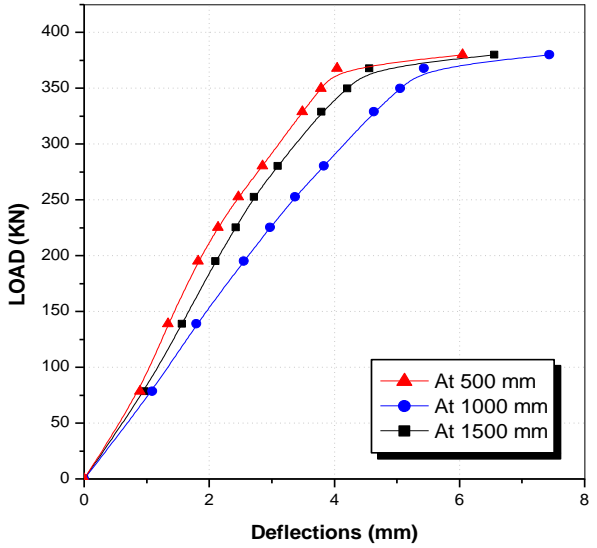

(a)

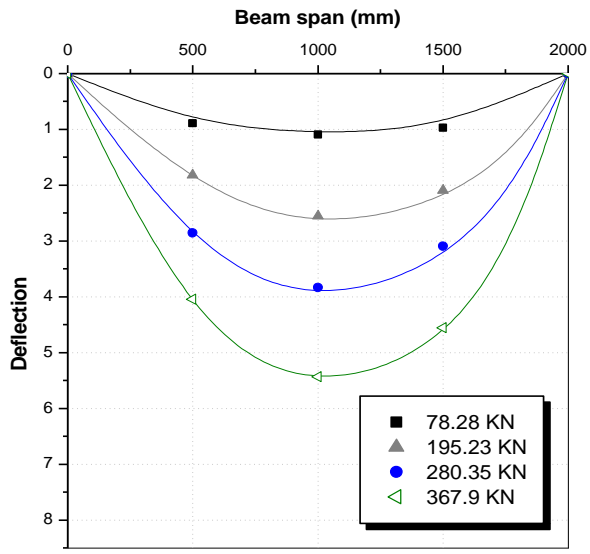

(b)

Fig.9: Load-deflection and deflection location curves for specimen S3

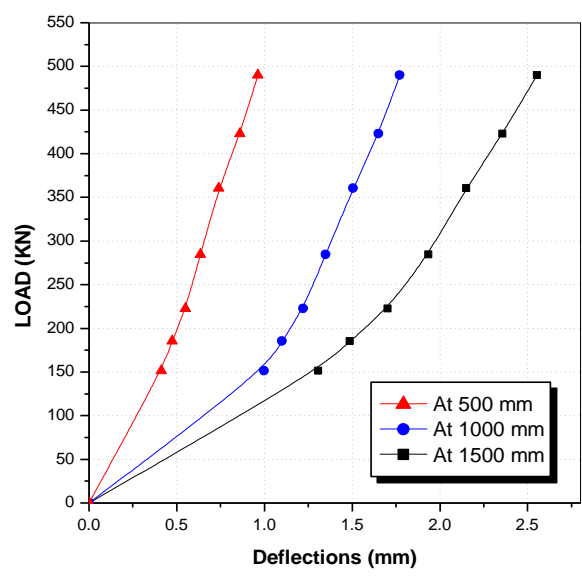

(a)

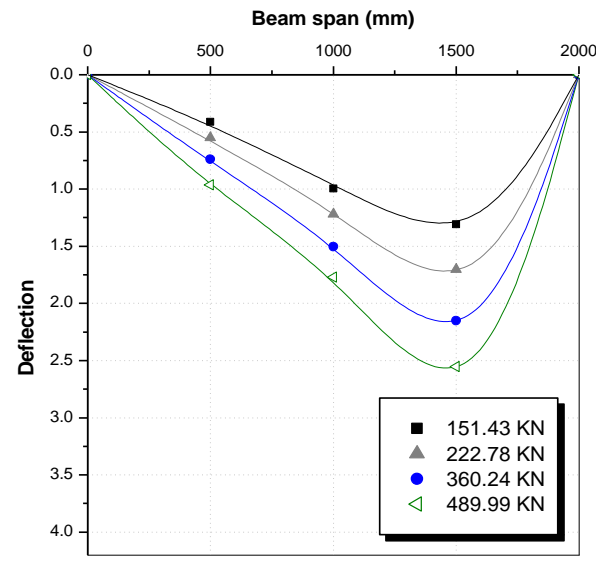

(b)

Fig.10: Load-deflection and deflection location curves for specimen S4

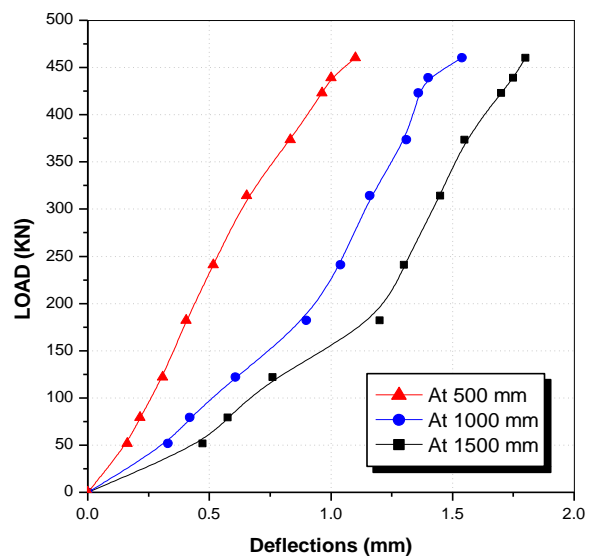

(a)

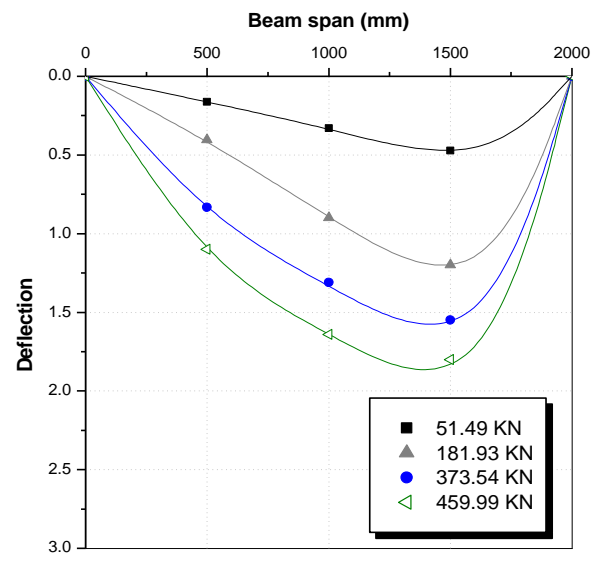

(b)

Fig.11: Load-deflection and deflection location curves for specimen S5 
The load deflection curves for the first three specimens, S1, S2, and S3 (Bending case) at mid span point, Figs. (7a, 8a, and 9a) showed that, the first two beams (S1, S2) have the same behavior as it is almost linear and they have the same deflection at the same load but the beam S2 failed at an early load of 292.7 KN. For specimen S3, which has increasing in stirrups distribution under the implanted column, gives less deflection values at the same load and more stiff and recorded failure load of $367.9 \mathrm{KN}$ which is more than the failure load of specimen S1 which failed at 338.3 KN. It was noted that the increase of the stirrups under the implanted column in beam S3 has a good influence on the beam behavior which gives less deflection values and higher failure load. For specimen S4 and S5, the deflection for the two specimens was taken at a point which located at $1500 \mathrm{~mm}$ from the left support. The behavior of the two specimens in the beginning of loading is almost typical after which the specimen S4 becomes stiffer. This is because it gives less deflection value at the same load until the failure load which is approximately the same. It was noted that the failure occurred at the implanted column cross section for both specimens.

At the mid-span of beams, the steel strains were measured for the main steel and the lower stirrups branch, at the point of the maximum moment for the first three specimens (S1, S2, and S3). At the end of the beam, the steel strain was measured in stirrups at the max shear for the last two specimens (S4 and S5). The measured strains as a function of the loading are drawn in Figure 12.a to Figure 12.e. The steel strain was measured at bottom reinforcement steel and stirrups under implanted column for specimens ( $\mathrm{S} 1$, S2, and S3). Also, the steel strain was measured at shear reinforcement main stirrups for specimens (S4, and S5).

From these curves, it is clear that the strain in bottom reinforcement steel for S1, S2, and S3 reaches yield strain. While the stirrups reinforcement didn't reach to yield strain for all specimens. This means that, beams for S4 and S5 failed which is due to compression stress of the beam exceeded the maximum compression stress of the implanted column.

\section{Data Analysis}

This part presents the analysis and the discussion of the test results to illustrate the effect of the following parameters on the flexural capacity of concrete beams in different cases:

\subsection{Effect of the Implanted Column Direction in Case of Bending}

This parameter was studied for the specimens S1 and S2. The tested beams had the same concrete dimensions, tension and shear reinforcement. The two specimens had also the same implanted column dimension and reinforcement but differed in the column direction.

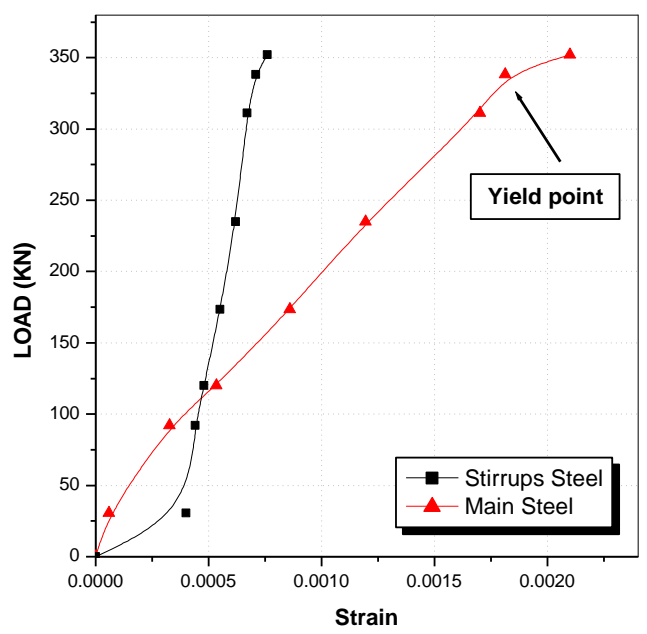

Fig.12.a: Steel-strain curves for S1

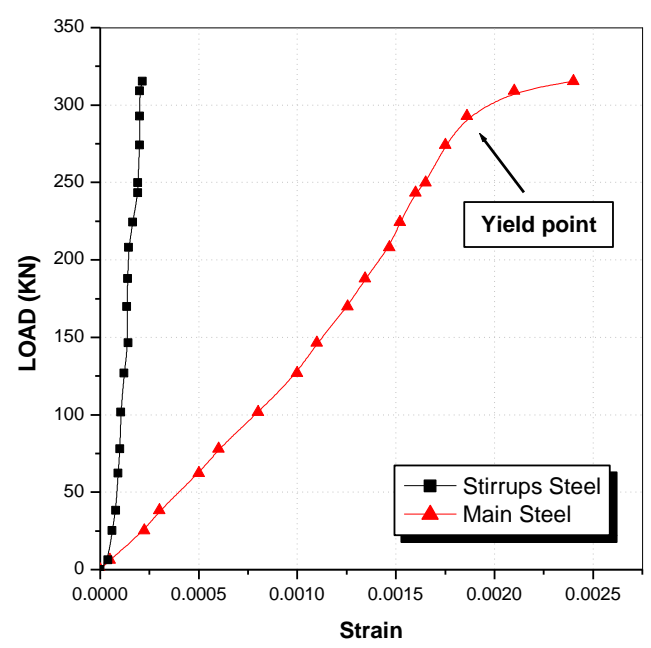

Fig.12.b: Steel-strain curves for S2

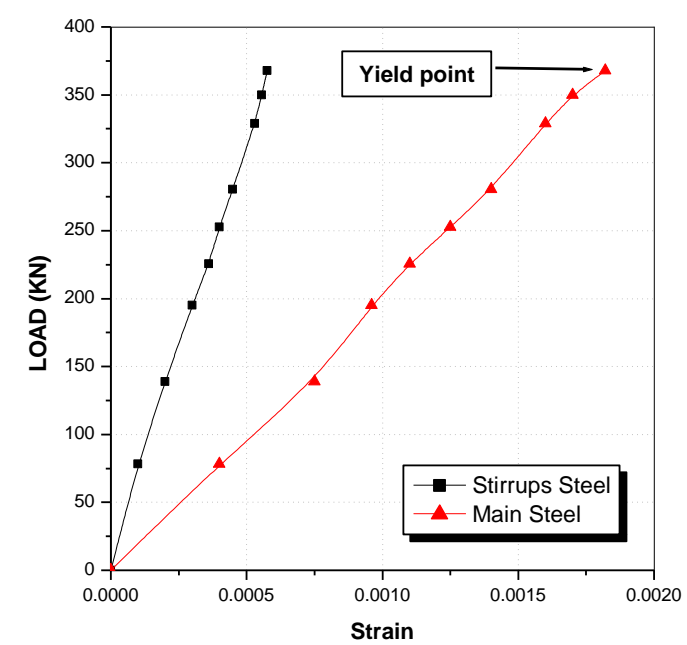

Fig.12.c: Steel-strain curves for $\mathrm{S} 3$ 


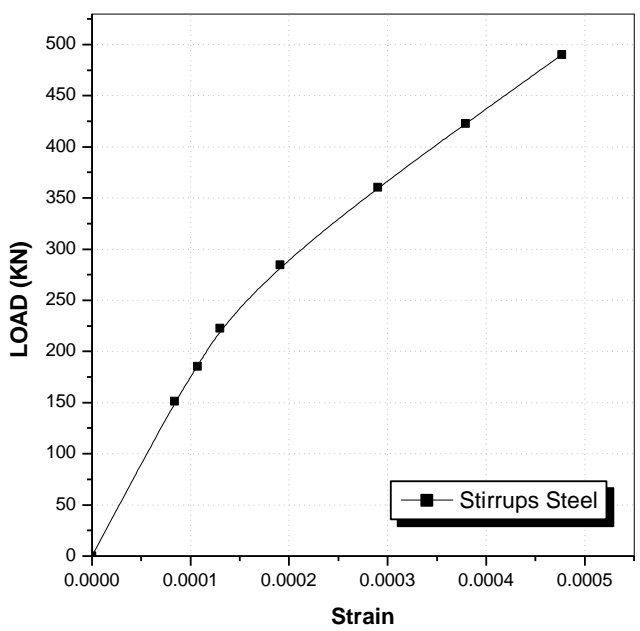

Fig.12.d: Steel-strain curves for S4

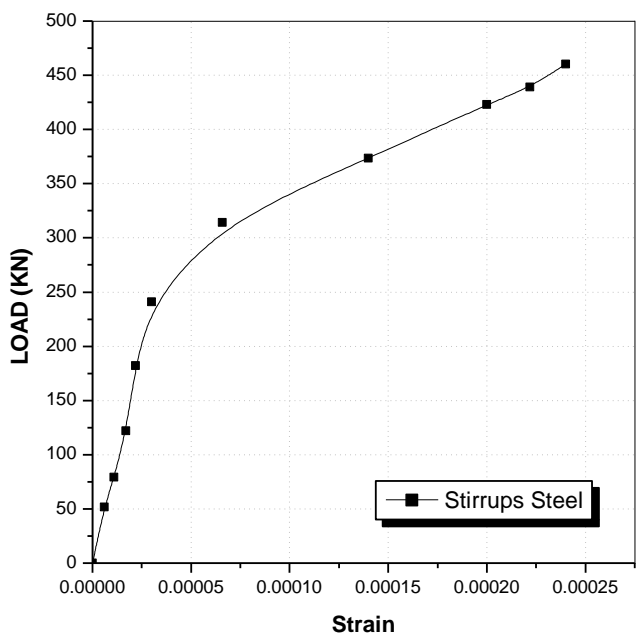

Fig.12.e: Steel-strain curves for S5

Specimen (S1) has the long side of the column direction perpendicular to the beam span and specimen (S2) has the long side of the column direction parallel to the beam span. The beam (S1) is more ductile than beam (S2) and the appearance of first crake load and failure load of $230 \mathrm{KN}$ and $338.3 \mathrm{KN}$, respectively for (S1), are larger than those for (S2) which are $127 \mathrm{KN}$ and $292.7 \mathrm{KN}$, respectively. The strain in the main steel for both specimens occurred at the failure load of each specimen, Fig. 12.a and Fig. 12.b showed the relation between the load and the strain in the tension steel. It was noticed that changing long column direction to be parallel to the beam span leads to a reduction in the flexure capacity of the beam.

\subsection{Effect of Increasing Distribution of Stirrups under the Implanted Column in Case of Bending}

The specimen S3 presented this parameter where it resembles specimen $\mathrm{S} 2$ but differs in stirrups volume to be $\varnothing 8 @ 100 \mathrm{~mm}$ in the zone under the implanted column. The beam S3 was found stiffer than beam S2 as it has a less deflection at the same load Fig. 9.a. A good enhancement in beam S3 was noticed compared with beam S2 in both first crake load (225 KN) and failure load (367.9) as shown in Table 3. These values are near those of S1 which are $230 \mathrm{KN}$ and $338.3 \mathrm{KN}$ respectively. The strain in the main steel also occurred at the failure load as shown in Fig. 12.c. It was noticed that, increasing in the distribution of stirrups under the implanted column has a good influence in increasing the failure load and reducing of deflection which gives a good solution for the problem of changing the column direction and subsequently the dropping in the value of the failure load.

\subsection{Effect of Changing the Location of the Implanted Column on the Shear Capacity}

The specimens S4 and S5 present this parameter in which, the beams have the same dimensions and shear reinforcement in bending but differed in the location of the implanted column. In specimen S4 the face of the implanted column is at the end of the beam. While in specimen S5 the face of the column is far by $120 \mathrm{~mm}$ from the end of the beam. The behavior of the two specimens is actually the same as the failure occurred in the implanted column with small propagation of shear cracks and low deflection values on the beam. The strain in the shear steel didn't reach the yield value at the failure load. It was noticed that, the column height increased the depth which resists shear. Therefore, compression failure occurred on the implanted column with small propagations of shear cracks.

\section{Conclusions}

The following conclusion can be deduced:

- In case of the length of the implanted column is perpendicular to beam span, which is the best position in the bending case, gives the bigger beam capacity and failure load compared with other positions.

- In case of the length of the implanted column is parallel to beam span, which is the worst position in the bending case, a great drop in the beam capacity and failure load occurred.

- Increasing the distribution of the stirrups under the implanted column, which is parallel to beam span, gives a noticed enhancement in the load failure and good recovery in the beam capacity.

- The design of the beam to satisfy the shear formed by the applied load near the support is sufficient and conservative as presented in of the implanted column near the support and its cross section increased the depth which resists shear.

\section{References}

Kokusho S., Hayashi S., Wada A. and Sakata H. (Aug 1988), Behaviors of Reinforced Concrete Beam Subjected to the Axial Restriction of Deformation, Ninth World Conference on Earthquake Engineering, Tokyo-Kyoto, Japan 
Hansapinyo C., Maekawa K. and Chaisomphob T. (2003), Behavior of Reinforced Concrete Beams Subjected to Biaxial Shear, Journal of Materials, Concrete Structures and Pavements, JSCE, V-58, No. 725, 321-331.

Chaisomphob T., Kritsanawonghong S. and Hansapinyo C. (2003), Experimental Investigation on Rectangular Reinforced Concrete Beam Subjected to Bi-axial Shear and Torsion, Songklanakarin Journal Science and Technology, 25(1), 41-52
Waryosh W.A., Mohaisen S.K. and Yahya L.M. (2014), Behavior of Rectangular Reinforced Concrete Beams Subjected to Bi-axial Shear Loading, Journal of Engineering and Development, Vol. 18, No. 2, ISSN 1813-7822

ACI Committee 318 (2011), Building Code Requirements for Structural Concrete and Commentary, (ACI 318M-11) American Concrete Institute

JSCE Committee (2007), Standard Specification for Design and Construction of Concrete Structure, Part 1 (Design), Tokyo: Japan Society of Civil Engineers, 2007. 